\title{
Análisis de la movilidad de los fisioterapeutas españoles en el contexto de la Unión Europea
}

\author{
Analysis of the mobility of Spanish physiotherapists in the context of the European \\ Union
}

\author{
S. Souto Camba ${ }^{\mathrm{a}}$, S. Marqués Varela ${ }^{\mathrm{b}}$, L. González Doniz ${ }^{\mathrm{a}}$, R. Fernández Cervantes ${ }^{\mathrm{a}}$ y \\ A. López Garcia ${ }^{\mathrm{a}}$
}

${ }^{a}$ Departamento de Fisioterapia, Grupo de investigación en Intervención Psicosocial y Rehabilitación Funcional, Red Salud, Bienestar físico y psicológico, Universidad de A Coruña, A Coruña, España

${ }^{b}$ Clínica de Fisioterapia Bergantiños, Carballo, A Coruña, España

\begin{abstract}
Resumen
Objetivo: Analizar la movilidad de los fisioterapeutas españoles en el contexto de la UE entre los años 1997.2012 al amparo de la Directiva 2005/36/EC.

Material y métodos: Búsqueda de información en la base de datos de la Comisión Europea (CE) en el mes de enero de 2014. Se han incluido en el análisis los países pertenecientes a la UE, centrándonos en el reconocimiento profesional, excluyendo los datos relativos a la movilidad temporal.

Resultados: La fisioterapia en España es la cuarta profesión más móvil a países europeos entre el año 1997 y el 2012. Los países que más solicitudes de reconocimiento profesional acumulan por parte de nuestros profesionales son Francia, Italia, Reino Unido, Portugal e Irlanda, seguidos de Bélgica y Alemania. Las solicitudes realizadas por años muestran un pico máximo de solicitudes de reconocimiento profesional en el año 2011. Los países que emiten un mayor número de reconocimientos positivos son Portugal, Italia y Bélgica y los que menos Irlanda, Francia y Alemania. Irlanda concentra también el mayor porcentaje de situaciones neutrales de reconocimiento, seguida de Francia.

Conclusiones: La fisioterapia española presenta una alta movilidad hacia Europa. Los 7 países de mayor demanda son Francia, Italia, Reino Unido, Portugal, Irlanda, Bélgica y Alemania. Los países que más fácilmente reconocen las cualificaciones profesionales de los fisioterapeutas españoles son Portugal, Italia y Bélgica. Los países que más dificultan esta movilidad son Irlanda y Alemania. La medida complementaria más adoptada para otorgar un reconocimiento positivo es la realización de un periodo de adaptación.
\end{abstract}

\section{Palabras clave}

Fisioterapia; Unión Europea; Mercado común europeo

\begin{abstract}
Objective: To analyze the mobility applications of Spanish physiotherapists in the context of the European Union between 1997 and 2011, according to Directive 2005/36/EC.

Material and methods: The research has been carried out with the database of the European Commission (EC) in January of 2014. All countries belonging to the EU have been included, focusing on professional recognition and excluding data concerning temporary mobility. Results: Physiotherapy is the fourth most mobile profession in Spain between 1997 and 2012. The most demanding host countries for professional recognition were France, Italy, United Kingdom, Portugal and Ireland, followed by Belgium and Germany. The peak of maximal applications for professional recognition occurs in 2011. Hosted countries with a greater number of positive recognitions were Portugal, Italy and Belgium. On the other hand, Ireland and Germany have the highest rate of negative recognitions. Ireland also has the largest number of neutral recognition situations.

Conclusions: Spanish Physiotherapy demonstrates a high mobility through Europe. The seven most demanded host countries were France, Italy, United Kingdom, Portugal, Ireland, Belgium and Germany. Countries where the professional qualifications recognition is easiest to achieve are Portugal, Italy and Belgium. Countries where it is more difficult are Ireland and Germany. The complementary requirement more frequently adopted to give the positive recognition is the development of an adaptation period in the host country.
\end{abstract}

Keywords

Physical therapy speciality; European Union; European Common Market 


\section{Introducción}

Las transformaciones que han experimentado las sociedades avanzadas fruto del desarrollo de las infraestructuras físicas y las telecomunicaciones, así como las exigencias de flexibilidad geográfica cada vez mayores en el mercado de trabajo o la mayor capacidad móvil de la sociedad en su conjunto, devienen necesariamente en un aumento de la demanda de movilidad a los profesionales y trabajadores ${ }^{1}$. La libre circulación de los trabajadores está establecida en el artículo 39 del Tratado de la Comisión Europea (CE) y desarrollada en el Reglamento 1612/68, por la que se establece el derecho de los ciudadanos de la Unión Europea (UE) a trabajar en otros Estados miembros ${ }^{2}$, En este sentido, la creación de un mercado único constituyó un proyecto complejo que ha permitido la desaparición de las barreras que impedían o dificultaban los desplazamientos de los ciudadanos europeos entre los distintos Estados miembros de la $\mathrm{UE}^{3}$. A nivel laboral, la movilidad debe permitir hacer frente a los nuevos retos que se le presupone a una sociedad avanzada y a un mercado de trabajo en constante evolución, sobre todo si se tienen en cuenta las nuevas posibilidades de que disponen los trabajadores y los empresarios tras la ampliación de la $\mathrm{UE}^{1} \bullet$

La salud constituye uno de los sectores más importantes de la economía de la UE, dando empleo a una de cada 10 personas de su población activa, en donde aproximadamente el $70 \%$ del presupuesto sanitario se destina a sueldos y otros gastos directamente relacionados con el empleo del personal sanitario ${ }^{2}$, Según datos de la Organización Mundial de la Salud, la región europea de este organismo cuenta con más de 16,6 millones de trabajadores en el sector salud. Alrededor del $70 \%$ de los profesionales de la salud proporcionan servicios de salud. El $30 \%$ restante ofrecen servicios de gestión y apoyo ${ }^{4}$.

El envejecimiento de la población es una tendencia demográfica en la UE. El aumento de los problemas de salud crónicos en la población anciana ha incrementado la demanda de trabajadores de la salud. Pero a medida que la población envejece, también lo hace el personal laboral. Entre 1995-2000, el número de médicos por debajo de 45 años en toda Europa descendió un 20\%, mientras que el número de mayores de 45 años aumentó en más de un 50\%. Así, para las enfermeras, las edades promedio están aumentando. En países como Dinamarca, Francia, Islandia, Noruega y Suecia, la edad promedio de las enfermeras que trabajan hoy en día es de 41-45 años ${ }^{4}$, A medida que personal se acerque a la jubilación será necesario que existan suficientes contratos de gente joven para reemplazarlos.

Por tanto, las tendencias demográficas a nivel poblacional, y su impacto sobre el personal sanitario, hacen prever un incremento de la movilidad de los profesionales de la salud dentro de los países de la UE, ayudando a corregir los desequilibrios entre los países que o bien tienen muchos profesionales, o bien pocos, en un campo determinado. En la actualidad, más y más profesionales de la salud deciden buscar oportunidades de empleo y de formación en otro país de la UE.

Dentro de la UE, si un profesional desea practicar o dar servicios en otro país necesita declarar su cualificación profesional, o que esta le sea reconocida por el país receptor. En ese sentido, es necesario considerar:

1. El concepto de profesión regulada implica que el acceso al ejercicio profesional está sujeto a la posesión de una cualificación acorde a las regulaciones o leyes nacionales. A lo largo de los 27 estados miembro de la UE hay reconocidas 800 categorías de profesiones reguladas, entre las que se encuentra la fisioterapia.

2. Que los requisitos de formación para obtener estas cualificaciones profesionales pueden variar de un país a otro y, por lo tanto, podrían hacer la práctica de una determinada profesión en otro país miembro bastante complicada e incluso imposible.

Para solucionar el problema que supone el reconocimiento de cualificaciones profesionales en Europa, la UE desarrolla la Directiva 2005/36/CE. Entre sus objetivos se encuentran los de servir de marco en el contexto europeo para la movilidad de profesionales, con el fin de ayudar a flexibilizar los mercados de trabajo, conseguir una mayor liberalización de la prestación de servicios y fomentar un reconocimiento más automático de las cualificaciones profesionales, simplificando los procedimientos administrativos. Todo ello, salvaguardando al mismo tiempo la protección del consumidor, la salud pública y la seguridad, así como el mantenimiento de los estándares profesionales. La directiva, que entró en vigor en octubre de 2007 y vino a sustituir a 15 directivas existentes en este ámbito del reconocimiento de las cualificaciones profesionales, proporcionando la primera modernización integral del sistema de la UE desde su introducción hace más de 40 años, se aplica a los profesionales que desean establecerse de manera permanente en un país de la UE diferente al país en el que obtuvieron su cualificación profesional. Además, establece un régimen especial de movilidad temporal. En estos casos, los profesionales pueden, en principio, trabajar en el país receptor con base en una declaración anticipada. No obstante, en las profesiones con implicaciones para la salud pública o la seguridad, como es el caso de las sanitarias, está 
permitida una comprobación inicial de cualificaciones. ${ }^{5}$. La directiva establece 3 sistemas para el reconocimiento de las cualificaciones (fig. 1$)^{5}$ :

1. El reconocimiento automático para las profesiones en las que las condiciones mínimas de formación han sido armonizadas dentro de la UE (médicos, enfermeras, matronas, farmacéuticos, arquitectos y veterinarios).

2. El sistema general de reconocimiento para otras profesiones reguladas, en el que se encuadra la fisioterapia.

3. El reconocimiento sobre la base de la experiencia profesional en determinadas actividades profesionales.

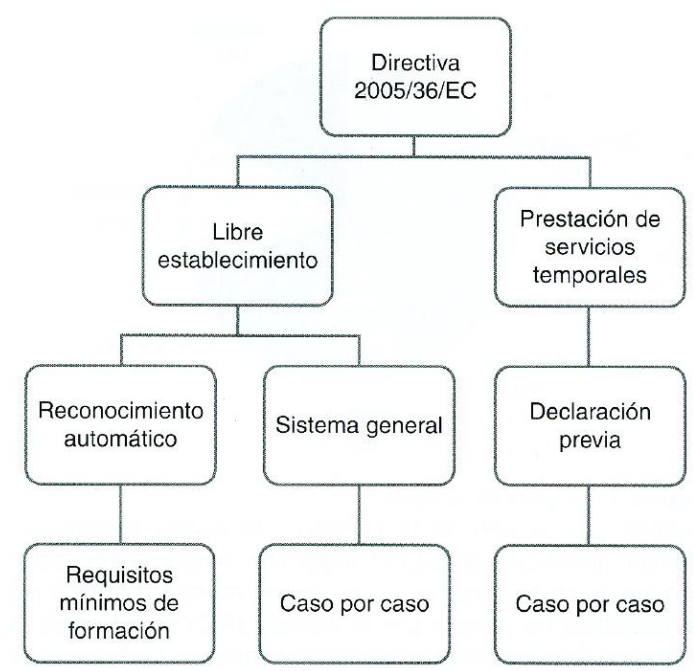

Figura 1. Diagrama sobre el reconocimiento de las cualificaciones profesionales de la directiva 2005/36/EC.

Dentro del sistema general, cada país será responsable en última instancia de aprobar o denegar caso a caso las peticiones de movilidad, pudiendo otorgar el reconocimiento automático (positivo automático), o condicionar el positivo/negativo a la realización de una prueba de actitud o un periodo de adaptación. La prueba tiene como objetivo el control relativo exclusivamente a los conocimientos profesionales del solicitante, y será efectuada por las autoridades competentes del Estado receptor, con el fin de evaluar la capacidad del solicitante para ejercer una profesión regulada en dicho Estado. En el caso del periodo de adaptación, este consistirá en el ejercicio de una profesión regulada en el Estado receptor bajo la responsabilidad de un profesional cualificado de la profesión. El periodo de práctica puede ser eventualmente acompañado de una formación complementaria.

Según datos oficiales de la CE, la fisioterapia destaca como la cuarta profesión con más movilidad dentro la UE, detrás de los médicos, los enfermeros y los profesores de secundaria, (http://ec.europa.eu/internal_market/qualifications/regprof/index.cfm?action=staLranking\&b_

services=false). Entre 1997-2012, Alemania, Holanda, Bélgica, Polonia y España fueron los 5 países en los que más fisioterapeutas solicitaron movilidad hacia otro país (fig. 2). Por otra parte, los 5 países receptores que más reconocieron los títulos profesionales de los fisioterapeutas provenientes de otros países fueron Austria, Alemania, Reino Unido, Francia y Noruega (fig. 3). 


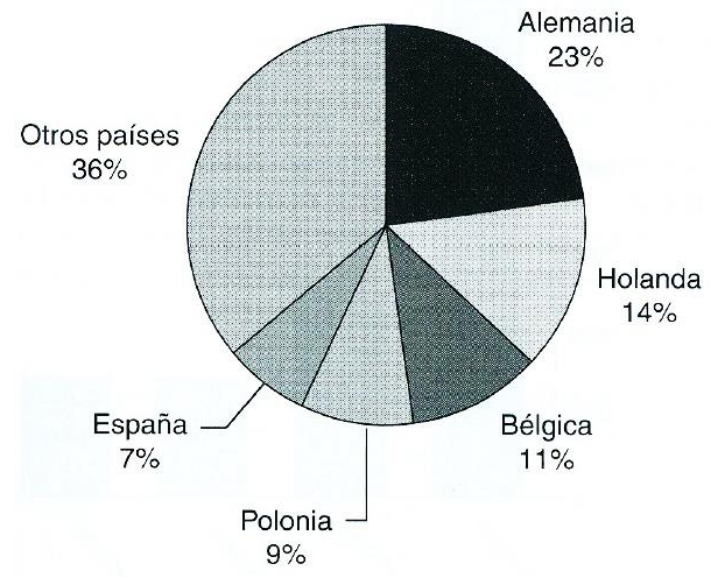

Figura 2. Países emisores de profesionales.

Fuente: página web de la CE

http://ec.europa.eu/internal_marketlqualifications/regproflindex.cfm (enero 2014) (establecimiento profesional en el extranjero, movilidad geográfica, y rellenando los campos con el periodo 1997/98-2012 para la profesión de fisioterapeuta en todos los países de la UE teniendo en cuenta cualquier decisión del país de acogida).

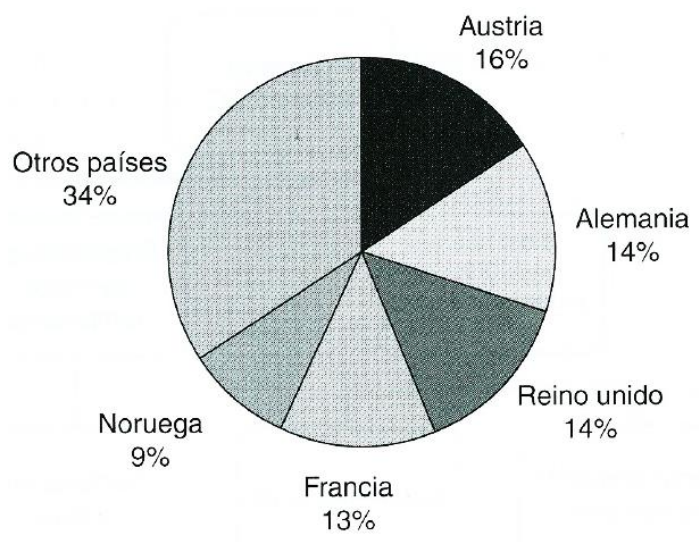

Figura 3. Países de acogida.

Fuente: página web de la CE http://ec.europa.eu/internal_marketl qualifications/ regprof /index.cfm (enero 2014) (establecimiento profesional en el extranjero, movilidad geográfica, y rellenando los campos con el periodo 1997/98-2012 para la profesión de fisioterapeuta en todos los países de la UE teniendo en cuenta cualquier decisión del país de acogida).

El objetivo de este estudio es analizar las solicitudes de movilidad de los fisioterapeutas españoles hacia otros países miembros de la UE, entre los años 1997-2012. Más específicamente se pretende:

a. Observar las tendencias de movilidad de los fisioterapeutas españoles por países y años.

b. Analizar el reconocimiento que las cualificaciones como fisioterapeuta obtenidas en España tienen bajo la aplicación de la Directiva 2005/36/EC.

c. Describir las diferencias existentes en el reconocimiento de dichas cualificaciones entre los principales países receptores. 


\section{Material y métodos}

La estrategia de búsqueda seguida es la de consultar la base de datos de la página web de la «European Comission»(CE) en su apartado de Mercado Único de la UE («TheEU Single Market») de servicios, sobre la libre circulación de los profesionales («free movement of professionals»), cuyos datos han sido extraídos en enero del 2014. Los países que se han incluido para el análisis son los pertenecientes a la UE. Quedan excluidos del análisis por lo tanto Islandia, Noruega, Suiza y Liechtenstein.

Se han considerado las solicitudes de establecimiento para el desarrollo profesional, excluyendo las de movilidad temporal, acorde al sistema general que rige para los fisioterapeutas. Para el análisis, se ha procedido de la siguiente manera:

1. En primer lugar se ha efectuado un análisis global para el período 1997-2012, observando las solicitudes totales de reconocimiento, y las solicitudes por países.

2. Se ha realizado un análisis de las solicitudes por año, para observar las tendencias en el período 19972012 en cuanto a países y grado de reconocimiento.

3. Finalmente se han seleccionado los 7 países más demandados y se ha analizado el estado de las peticiones en cada uno de ellos, en el periodo 1997-2012. Se han considerado globalmente las solicitudes positivas, negativas y neutras. Las positivas engloban aquellas que se reconocen automáticamente por el sistema general o por la experiencia profesional y las que se establecen después de una prueba de aptitud o después de un período de adaptación. Son consideradas negativas aquellas en las que existe una negación automática por el sistema general o por la experiencia profesional, después de una prueba de aptitud o después del período de adaptación. Las neutras recogen aquellos casos que se han recurrido, que están siendo sometidos al período de adaptación o que están siendo examinadas.

\section{Resultados}

Las estadísticas generales muestran que la fisioterapia en España, comparativamente a otras profesiones de nuestro país, es la cuarta profesión con mayor solicitud de movilidad, después de los profesores de secundaria, los enfermeros y los médicos con un total de 1.434 peticiones para el reconocimiento de la profesión en otros territorios europeos entre el año 1997 y el 2012 (fig. 4).

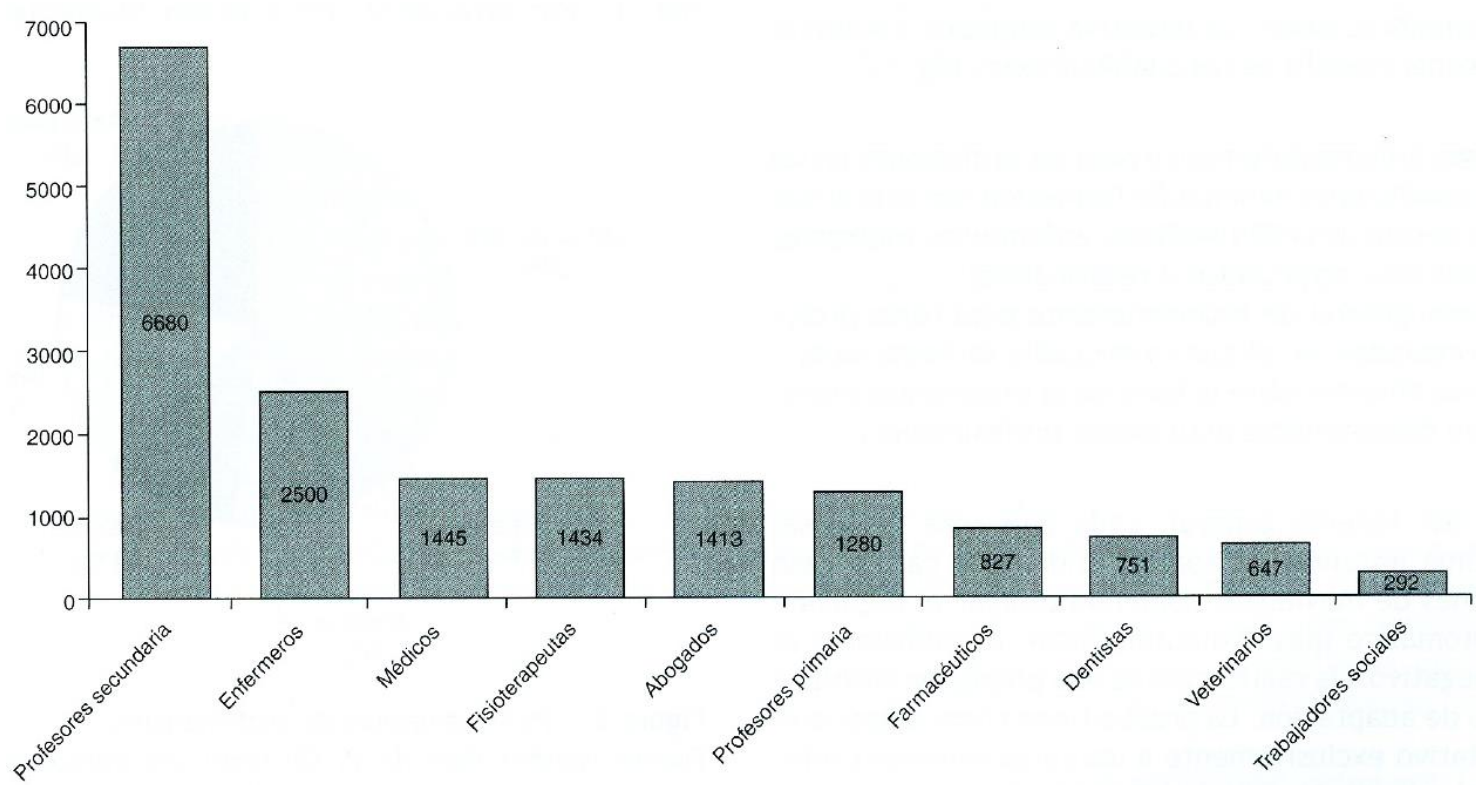

Figura 4. Ranking de peticiones de las diferentes profesiones en España para el reconocimiento de sus cualificaciones en Europa. Fuente: página web de la CE: http://ec.europa.eu/internal_marketlqualifications/regprof/index.cfm (enero 2014) (establecimiento profesional en el extranjero, ranking de las profesiones más móviles, y rellenando los campos con el periodo 1997/98-2012 para la profesión de fisioterapeuta con España como país emisor y todos los países de la UE como países huésped). 
La tabla 1 recoge el número total de fisioterapeutas españoles que han solicitado el reconocimiento en los diferentes países de la UE en el período de estudio. Como se puede observar, los principales países para los que se han tramitado las solicitudes son Francia, Italia, Reino Unido, Portugal e Irlanda, suponiendo los 92,81\% del total de las solicitudes, seguidos de Alemania y Bélgica.

Tabla 1. Número de fisioterapeutas españoles que han solicitado el reconocimiento de sus cualificaciones por países

\begin{tabular}{lclclc}
\hline Alemania & 32 & Finlandia & 5 & Luxemburgo & 2 \\
\hline Austria & 12 & Francia & 635 & Malta & - \\
Bélgica & 30 & Grecia & 2 & Polonia & - \\
Bulgaria & - & Holanda & 3 & Portugal & 79 \\
Chipre & - & Hungría & - & Rumania & - \\
Dinamarca & 4 & Irlanda & 40 & Suecia & 13 \\
Estonia & - & Italia & 448 & Rep. Checa & - \\
Eslovaquia & - & Letonia & - & Reino Unido & 129 \\
Eslovenia & - & Lituania & - & & \\
\end{tabular}

Fuente: elaboración propia

En la figura 5 se analizan las solicitudes realizadas por años, observándose una tendencia lineal que presenta 2 repuntes fundamentales: el que va del año 1997-2004 y el más marcado en el año 2011, en el que se acumulan 651 solicitudes.

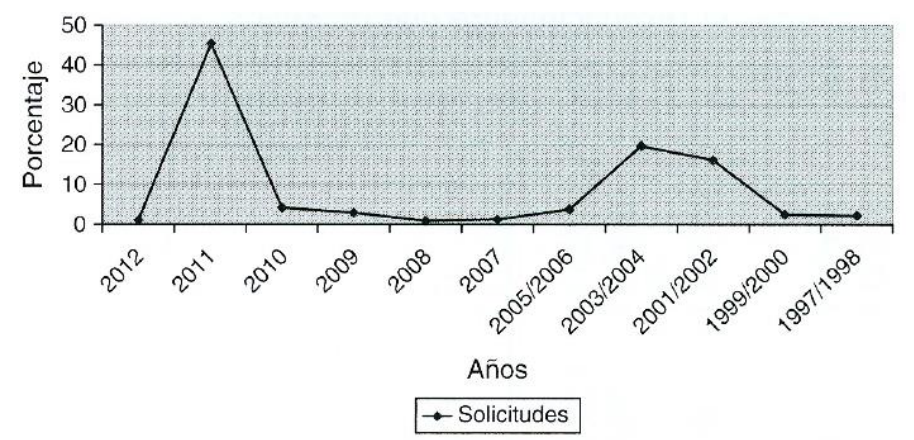

Figura 5. Porcentajes de solicitudes por años. Fuente: elaboración propia

La tabla 2 recoge con detalle las solicitudes por países y por años. Francia acumula un mayor número de solicitudes, tramitadas preferentemente en el año 2011 (el 99,05\%). En el caso de Italia, segundo destino por orden de preferencia de los fisioterapeutas españoles a la hora de solicitar el reconocimiento, más de la mitad de las peticiones se tramitaron en el periodo 200312004 (el 53,12\%). Reino Unido, Alemania y Bélgica son los países europeos para los que se observa una mayor constancia a lo largo de los años en el número de solicitudes realizadas. En el caso de Portugal, las solicitudes se concentran entre 2001-2004, y para Irlanda mayoritariamente en los periodos 2001/2002 y 2005/2006. 
Tabla 2 Solicitudes realizadas por año y por país, expresadas en términos absolutos y como porcentaje

\begin{tabular}{|c|c|c|c|c|c|c|c|c|c|c|c|c|}
\hline & 2012 & 2011 & 2010 & 2009 & 2008 & 2007 & $2005 / 2006$ & $2003 / 2004$ & $2001 / 2002$ & $1999 / 2000$ & 1997/1998 & Total \\
\hline Austria (\%) & $4(33,33)$ & & & & $1(8,34)$ & & $4(33,33)$ & & $1(8,34)$ & $2(16,66)$ & & 12 \\
\hline Bélgica (\%) & & $5(16,66)$ & $6(20)$ & $5(16,66)$ & $3(10)$ & $2(6,66)$ & $4(13,33)$ & $2(6,66)$ & & $3(10)$ & & 30 \\
\hline $\begin{array}{l}\text { Dinamarca } \\
(\%)\end{array}$ & & & & & & $1(25)$ & & & $1(25)$ & & $2(50)$ & 4 \\
\hline $\begin{array}{l}\text { Finlandia } \\
(\%)\end{array}$ & & & & $1(20)$ & & & $2(40)$ & $2(40)$ & & & & 5 \\
\hline Francia (\%) & & $629(99,05)$ & & & & & & & & & $6(0,95)$ & 635 \\
\hline $\begin{array}{l}\text { Alemania } \\
(\%)\end{array}$ & & $4(12,5)$ & & $1(3,125)$ & $3(9,375)$ & $3(9,375)$ & $1(3,125)$ & $3(9,375)$ & $6(18,75)$ & $7(21,875)$ & $4(12,5)$ & 32 \\
\hline Grecia (\%) & & & $1(50)$ & $1(50)$ & & & & & & & & 2 \\
\hline Irlanda (\%) & & & & $1(2,5)$ & & & $9(22,5)$ & $4(10)$ & $25(62,5)$ & & $1(2,5)$ & 40 \\
\hline Italia $(\%)$ & & & $40(8,93)$ & $25(5,58)$ & & & & $238(53,125)$ & $139(31,03)$ & $4(0,9)$ & $2(0,44)$ & 448 \\
\hline $\begin{array}{l}\text { Luxemburgo } \\
\text { (\%) }\end{array}$ & & & & & & $1(50)$ & $1(50)$ & & & & & 2 \\
\hline Holanda (\%) & & & & & & & & & $1(33,33)$ & $1(33,33)$ & $1(33,33)$ & 3 \\
\hline Portugal (\%) & & & $1(1,26)$ & & & $1(1,26)$ & & $21(26,58)$ & $56(70,88)$ & & & 79 \\
\hline Suecia $(\%)$ & & $1(7,692)$ & $1(7,692)$ & & & & & $5(38,46)$ & $2(15,384)$ & $3(23,076)$ & $1(7,692)$ & 13 \\
\hline $\begin{array}{l}\text { Reino Unido } \\
(\%)\end{array}$ & $\mathbf{1 1}(8,527)$ & $12(9,302)$ & $\mathbf{1 1}(8,527)$ & $8(6,201)$ & $6(4,651)$ & $10(7,751)$ & $33(25,581)$ & $7(5,426)$ & & $16(12,403)$ & $15(11,627)$ & 129 \\
\hline
\end{tabular}

Fuente: elaboración propia 
La tabla 3 recoge el estado de las peticiones por países en el periodo 1997-2012. Se observa que la mayor parte de las solicitudes son reconocidas positivamente $(61,09 \%)$, muy pocas son informadas de manera negativa $(1,07 \%)$ Y el resto están en situación neutra $(37,83 \%)$. Al realizar el análisis por países, se observa que el mayor número de reconocimientos positivos totales se produce en Portugal $(98,73 \%)$, Italia (86,83\%) y Bélgica (80\%), seguido de Reino Unido (63,57\%), Alemania $(56,25 \%)$ y Francia $(39,51 \%)$. El porcentaje más bajo de positivos se da en Irlanda que suponen un $22,5 \%$ del total de las solicitudes. En Portugal, Italia y Bélgica la totalidad de los positivos son concedidos de manera automática, sin necesidad de una prueba o periodo de adaptación. Reino Unido e Irlanda son los países en los que con más frecuencia se recurre a un periodo de adaptación para emitir un informe positivo, si bien lo hacen de manera inversa a la emisión de positivos automáticos: en Reino Unido la relación se aproxima al 2: 1 (esto es, por cada 2 positivos automáticos condicionan uno al periodo de adaptación), mientras que en Irlanda es 1: 3,5 (por cada reconocimiento auto- mático solicitan 3,5 periodos de adaptación). El único país que ha utilizado la prueba de aptitud para resolver positiva- mente alguna solicitud es Francia, aunque podríamos decir que de una manera anecdótica, ya que en este país la mayor parte de los positivos también son concedidos de manera automática (el 82,86\%) y tras periodo de adaptación (el 13,94\%).

En cuanto a las solicitudes denegadas, los países que han emitido informe negativo son Alemania (12,5\%), Irlanda (10\%), Reino Unido (3,87\%) y Francia (0,3\%). Portugal, Italia y Bélgica nunca han emitido un informe negativo. Todos los negativos que produce Alemania son de carácter automático. Irlanda, Reino Unido y Francia han emitido también negativos después de un período de adaptación. Francia vuelve a ser el único país que emite negativos tras hacer uso de las pruebas de aptitud aunque también de los períodos de adaptación, sin emitir en ningún caso un negativo automático,

El mayor número de situaciones neutrales se da en Irlanda, seguida por Francia, Reino Unido, Alemania, Bélgica, Italia y Portugal. En la mayor parte de los casos, esta situación de neutralidad se produce porque son solicitudes en trámite de examen. No obstante, excepto en Italia y Portugal, en todos los países hay solicitudes que están en periodo de adaptación, y en 3 casos (Reino Unido, Irlanda y Francia) es posible encontrar la existencia de recursos en trámite de resolución. 
Tabla 3. Resultados de las peticiones de movilidad a Francia, Italia, Reino Unido, Portugal, Irlanda, Bélgica y Alemania entre 1997-2012

\begin{tabular}{|c|c|c|c|c|c|c|c|c|c|c|c|c|c|}
\hline & \multicolumn{4}{|c|}{ Positivos } & \multicolumn{4}{|c|}{ Negativos } & \multicolumn{5}{|c|}{ Neutros } \\
\hline & $\begin{array}{c}\text { Automátic } \\
\text { o }\end{array}$ & $\begin{array}{l}\text { Después } \\
\text { prueba } \\
\text { actitud }\end{array}$ & $\begin{array}{l}\text { Después } \\
\text { periodo } \\
\text { adpatación }\end{array}$ & Totales & Automático & $\begin{array}{l}\text { Después } \\
\text { prueba } \\
\text { actitud }\end{array}$ & $\begin{array}{l}\text { Después } \\
\text { periodo } \\
\text { adpatación }\end{array}$ & Totales & $\begin{array}{l}\text { Han } \\
\text { recurrido }\end{array}$ & $\begin{array}{l}\text { En período de } \\
\text { adaptación }\end{array}$ & $\begin{array}{l}\text { En periodo } \\
\text { de examen }\end{array}$ & Totales & Total \\
\hline Francia (\%) & $208(32,75)$ & $8(1,25)$ & $35(5,51)$ & $251(39,51)$ & - & $1(0,15)$ & $1(0,15)$ & $2(0,3)$ & $34(5,35)$ & $182(28,66)$ & $166(26,15)$ & $382(60,16)$ & 635 \\
\hline Italia (\%) & $389(86,83)$ & - & - & $389(86,83)$ & - & - & - & - & - & - & $59(13,17)$ & $59(13,17)$ & 448 \\
\hline $\begin{array}{l}\text { Reino } \\
\text { Unido (\&) }\end{array}$ & $56(43,41)$ & - & $26(20,16)$ & $82(63,57)$ & $3(2,32)$ & - & $2(1,55)$ & $5(3,87)$ & $1(0,77)$ & $17(13,18)$ & $24(18,60)$ & $42(32,55)$ & 129 \\
\hline $\begin{array}{l}\text { Portugal } \\
(\%)\end{array}$ & $78(98,73)$ & - & - & $78(98,73)$ & - & - & - & - & - & - & $1(1,26)$ & $1(1,26)$ & 79 \\
\hline Irlanda (\%) & $2(5)$ & - & $7(17,5)$ & $9(22,5)$ & $3(7,5)$ & - & $1(2,5)$ & $4(10)$ & $6(15)$ & $2(5)$ & $19(47,5)$ & $27(67,5)$ & 40 \\
\hline Bélgica (\%) & $24(80)$ & - & - & $24(80)$ & - & - & - & - & - & $3(10)$ & $3(10)$ & $6(20)$ & 30 \\
\hline $\begin{array}{l}\text { Alemania } \\
(\%)\end{array}$ & $17(53,12)$ & - & $1(3,12)$ & $18(56,25)$ & $4(12,5)$ & - & - & $4(12,5)$ & - & $1(3,12)$ & $9(28,12)$ & $10(31,25)$ & 32 \\
\hline
\end{tabular}

Fuente: elaboración propia 


\section{Discusión}

El presente estudio se centra en analizar con un carácter descriptivo las solicitudes de reconocimiento de las cualificaciones profesionales del fisioterapeuta español a efecto de establecerse de manera permanente en un país miembro de la UE diferente, al amparo de la normativa europea 2005/36/EC. La información disponible muestra que España es uno de los países que más solicitudes de movilidad realiza para ejercer la fisioterapia en otro país, por detrás de Polonia, Bélgica, Holanda y Alemania. Internamente, en el periodo de 15 años que comprende el estudio y en términos absolutos, es la cuarta profesión española con más movilidad hacia Europa (con 1.434 solicitudes), después de la enfermería (en segundo lugar, con 2.500 solicitudes) y la medicina (en tercer lugar, con 1.445). Si comparamos la escasa diferencia existente entre las solicitudes de migración del colectivo de médicos y la del colectivo de fisioterapeutas (11 solicitudes) con el número de profesionales colegiados no jubilados en España para ambas profesiones (232.816 médicos vs. 39.936 fisioterapeutas) según datos del Instituto nacional de estadística del 2013 (http://www.ine.es/jaxi/menu.do?type= pcaxis\&file=pcaxis\&path=\%2Ft15\%2Fp416 $\% 2 \mathrm{~F} \% 2 \mathrm{Fa} 2013$ ), se observa claramente cómo la fisioterapia es una profesión con una elevada movilidad dentro de las ciencias de la salud. Profundizar en las causas de la misma está fuera del alcance del presente artículo, y serán futuras investigaciones las que deberán discernir si esto tiene o no que ver con el incremento del número de profesionales ejerciendo la profesión en nuestro país que se ha dado en los últimos años, pasando de 26.343 fisioterapeutas colegiados no jubilados en el año 2006, a 39.936 en el año 2013 (lo que supone un incremento del51\% en este periodo, frente al 10,73\% experimentado por la enfermería y el $14,63 \%$ por la medicina) según la misma fuente de datos citada anteriormente.

Otro hallazgo particularmente llamativo guarda relación con la progresión de las solicitudes a lo largo de los años, al observarse que el 45,11\% de las mismas tienen lugar en el año 2011 y en su mayoría están tramitadas para Francia. Quizás el factor acumulativo de los años de crisis económica haya impactado sobre una profesión que ejerce preferente- mente en el sector privado, sometida por tanto a las leyes de la oferta y la demanda, forzando a los profesionales a buscar una alternativa laboral en otro país. No obstante, este argumento de la crisis no explicaría el hecho de la disminución de solicitudes en el 2012, ni la demanda tan marcada de movilidad hacia Francia, concentrada en el año 2011 (en periodos anteriores desde el año 1997/98 hasta el 2011 - no se registra ningún dato de movilidad). Quizás el hecho de que los datos no tengan en consideración la movilidad temporal, y solo exclusivamente el establecimiento permanente en países mediante el reconocimiento profesional, pueda influir en este resultado.

Los países a los que prefieren migrar los fisioterapeutas españoles son, por orden decreciente, Francia, Italia, Reino Unido, Portugal, Irlanda, Alemania y Bélgica. Multitud de causas pueden guardar relación con estas preferencias, desde la propia proximidad geográfica (en el caso del Portugal y Francia) - en zonas limítrofes se da un mayor grado de movilídad ${ }^{6}-$, la facilidad para el conocimiento y aprendizaje del idioma (como el caso de Italia), el grado de desarrollo profesional de la fisioterapia en el país (factor que puede primar en países del ámbito anglosajón como Reino Unido o Irlanda), o factores de tipo socioeconómico y cultural, entre otros.

Del análisis del número de reconocimientos positivos, negativos y neutros que emiten estos países receptores, se puede inferir que en general los titulados españoles no tienen problemas para que sus cualificaciones sean reconocidas en Europa. Portugal, Italia y Bélgica son los países que más reconocen sin ningún tipo de traba, puesto que son los que conceden más positivos automáticos y no han denegado ninguna solicitud. Además, los pocos casos que tienen en situación neutral lo están preferentemente porque están siendo examinados. Esta realidad contrasta con la de países como Reino Unido, Irlanda y Alemania, que ponen más condicionantes para el reconocimiento positivo, preferentemente a través de periodos de adaptación en el país; y que emiten informes negativos, en el caso de Irlanda y Alemania, mayoritariamente de manera automática. Francia merece una mención aparte, ya que a pesar el alto número de solicitudes o quizás debido a ello, presenta un alto porcentaje de casos en situación neutral, la mayor parte de ellos bajo examen o en el periodo de adaptación. Además es el único país que contempla en algunos casos una prueba de aptitud para condicionar el reconocimiento positivo.

La movilidad de los profesionales está muy directamente ligada a su formación académica, no obstante, hay que señalar que para el propósito del reconocimiento la Directiva establece niveles de cualificación propios que no coinciden totalmente con los 3 ciclos académicos establecidos por el proceso de Bolonia". Además, las autoridades de cada país competentes para la resolución de las solicitudes pueden establecer criterios de tipo profesional que operan en cada país, marcados en muchas ocasiones por las organizaciones profesionales de la fisioterapia. Solo así se puede explicar que países con una estructura formativa académica similar, como es el caso de Irlanda con un grado en fisioterapia de 240 ECTS estructurado en 4 años, ponga trabas al reconocimiento; o que países como Bélgica, en el que el 
grado académico para el acceso a la profesión es el de máster, realice los reconocimientos de tipo automático. El caso de Alemania resulta particularmente llamativo, dado que la vía formativa tradicional y más extendida de los fisioterapeutas es la formación profesional o «vocational training», que coexiste en la actualidad con la formación superior en las universidades (Inventory on Physiotherapy Entry-Level of Education within the ER-WCPT. ER-WCPT: Malta, 2012. Observación no publicada). Solo un 2,3\% de los profesionales del país se han formado académicamente en instituciones de educación superior ${ }^{8}$.

Existen países a los que ningún fisioterapeuta español ha solicitado el reconocimiento profesional. Estos países han sido Bulgaria, Chipre, Estonia, Eslovaquia, Eslovenia, Hungría, Letonia, Lituania, Malta, Polonia, Rumania y República Checa. Este hecho podría justificarse porque los citados países han entrado a formar parte de la UE más tardíamente (en el período 2004-2007), el escaso nivel de desarrollo profesional de la fisioterapia en el país (en algunos casos está sin regular) o la dificultad añadida que supondría el aprendizaje de sus lenguas oficiales, no descendientes en su mayoría de las lenguas latinas. Las diferencias lingüísticas, sociales y culturales se consideran un obstáculo a la movilidad ${ }^{9}$.

El presente estudio se basa en los datos consultados sobre las solicitudes de movilidad permanente para ejercer profesionalmente en otro país, pero en ningún caso aportan información sobre si el profesional finalmente ocupó un puesto en el país una vez se obtuvo el reconocimiento positivo, si el profesional se movió a un tercer país, o si retornó a su país de origen. Por lo tanto, estos datos solo pueden ser usados como una aproximación al tema de la movilidad profesional en ausencia de una información más detallada. Las solicitudes en situación de neutralidad podrían modificar la realidad aquí reflejada a medida que se resuelvan los expedientes. El estudio tampoco aporta información sobre las universidades de procedencia que otorgaron el título en España, para observar si existen diferencias a la hora del reconocimiento de los títulos por parte de las autoridades de cada país receptor.

Será interesante observar lo que sucede en los próximos 10 años con la movilidad de los fisioterapeutas españoles, si se cumplen las expectativas de que la fisioterapia incremente su demanda a raíz de 3 factores esenciales: el aumento de las patologías discapacitantes, el mayor conocimiento de las personas sobre la intervención del fisioterapeuta y la necesidad de prevención y promoción que contribuya al descenso de los índices de morbilidad ${ }^{10}$.

En el año 2016 la Directiva 2005/36/EC quedará derogada por la aplicación de la Directiva 2013/55/EU con nuevos elementos a considerar a la hora de migrar, como son la implementación de la Carta Profesional Europea (European Profesional Card), y en el caso de las profesiones sanitarias nuevos requisitos de cara a salvaguardar la seguridad de los ciudadanos y pacientes (como por ejemplo, normas sobre la competencia lingüística a la hora de ejercer).

A modo de conclusión, la fisioterapia española es una profesión que presenta una alta movilidad hacia Europa y cuyos profesionales son mayoritariamente reconocidos para el ejercicio de la profesión en los países receptores. Los 7 países a los que los fisioterapeutas españoles demandan una mayor movilidad son Francia, Italia, Reino Unido, Portugal, Irlanda, Bélgica y Alemania. De estos, los países que más fácilmente reconocen las cualificaciones profesionales de los fisioterapeutas españoles son Portugal, Italia y Bélgica. Los que más dificultan esta movilidad son Irlanda y Alemania. La medida complementaria más adoptada por los diferentes países para otorgar un reconocimiento positivo es la realización de un periodo de adaptación en el país receptor.

\section{Responsabilidades éticas}

Protección de personas y animales. Los autores declaran que para esta investigación no se han realizado experimentos en seres humanos ni en animales.

Confidencialidad de los datos. Los autores declaran que en este artículo no aparecen datos de pacientes.

Derecho a la privacidad y consentimiento informado. Los autores declaran que en este artículo no aparecen datos de pacientes.

\section{Conflicto de intereses}

Los autores declaran no tener ningún conflicto de intereses. 


\section{Bibliografía}

1. European Comission Health workforce [internet]. Brussels: European Comission; Green paper on the European Workforce for Health; 2008 [citado Mar 2013]; [aproximadamente 14 pantallas]. Disponible en: http://ec.europa.eu/health/ph.systerns/docs/workforce.gp.en.pdf

2. UGT Euskadi [internet]. Euskadi: Investigación social y de mercado. La movilidad laboral y el desarrollo económico. Análisis cuantitativo y cualitativo de la movilidad laboral en el eje Atlántico de la Unión Europea. Causas y tendencias; [citado Mar 2013]; [sobre 97 pantallas]. Disponible en: http://www.ugteuskadi.org/imagenes/Informe.Movilidad.pdf

3. Bizkaia.Net [internet].Bizkaia; Diputación foral de Bizkaia: guía de movilidad 2012, 2012; [cited Mar 2013]; [sobre 334 pantallas]. Disponible en: http://www.bizkaia.netlogasuna/europa/guía_movilidad/ca_guia_movilidad 2012. pdf

4. OMS. [internet]. Europe: Organización Mundial de la Salud; 2013; [citado Mar 2013]. Disponible en: http://www. who.int/es/

5. European Comission: public consultations [Internet]. Europe: European Comission; 2013. Internal Market: a single market for services: free movement of professionals; 2012 Nov 26 [citado Feb 2013]; [sobre 1 pantalla]. Disponible en: http://ec.europa.eu/internal_market/qualifications/index_en. htmc

6. Sellin B, La movilidad en Europa (UE y EEE). Un análisis centrado particularmente en las profesiones sanitarias y el reconocimiento de las respectivas cualificaciones. Revista Europea Formación Profesional. 2002;26:49-60. 7.ERWCPT [internet]. Europe: Región Europea de la WCPT: European Qualification Framework and its relations to the Bolognia cycles and directives on proffesional Qualifications; [citado Feb 2014]. Disponible en: http://erwcpt.eu/education/qualification_systemshttp://erwcpt.eu/education/qualification_systems

8. Scherfer, E. Visions, (Labour) Market and Politics. Current Issues of Physiotherapy Education in Germany between Vocational Training and Higher Education. En: Romanian Federation for Physiotherapy - FRAF National Congress. Bucuresti, October 2014.

9. Morrillas J. Movilidad en los nuevos mercados de trabajo de la UE. Boletín económico del ICE. 2001 ;2691:218.

10. Rodríguez YL, Sarmiento Fe. Caracterización de la formación en fisioterapia en países europeos. Movimiento científico. 2012;6:58-69. 